\title{
Analogical Reasoning in the Common Law
}

\author{
Grant Lamond ${ }^{*}$
}

\begin{abstract}
Analogical reasoning is a pervasive feature of the common law, yet its structure and rational force is much disputed by legal theorists, some of whom are sceptical that it has any rational force at all. This paper argues that part of the explanation for these disagreements lies in there being not one form of analogical reasoning in the common law, but three: classificatory analogies, close analogies, and distant analogies. These three differ in their functions and rationale. Classificatory analogies involve the use of decided cases to help characterize novel fact situations, and are justified by the rule of law ideal of minimizing the dependence of judicial decisions on the individual views of decision-makers. Close analogies are used to help resolve unsettled issues by reliance on decisions from other branches of the same legal doctrine. They complement the doctrine of precedent, and rest on similar considerations. Distant analogies are also used to help resolve unsettled issues, but by reference to decisions from other legal doctrines. They are the most susceptible to sceptical critique: although they can serve to maintain coherence in the law, they deserve a more modest role in legal reasoning than they are often given.
\end{abstract}

Key words: analogical reasoning, common law, legal reasoning, precedent, legal philosophy.

\section{Introduction}

The use of analogies is a standard feature of reasoning in the common law: judgments, opinions, and textbooks rely on them in discussing the state of the law in every area. Yet their precise role is a matter of considerable dispute among legal theorists. Some theorists regard them as the cornerstone of common law reasoning, ${ }^{1}$ while others regard them as mere window-dressing, without normative force. ${ }^{2}$ Others again argue that analogies owe their normative force, and their identification, to some independent element, such as principles ${ }^{3}$ or their rationale. ${ }^{4}$

\footnotetext{
* University Lecturer in Legal Philosophy and Fellow of Balliol College, University of Oxford. Email: grant.lamond@law.ox.ac.uk. I would like to thank the participants in the Oxford/Girona Legal Philosophy Workshop where some of the ideas in this paper were first presented. I would also like to thank James Goudkamp, John Stanton-Ife and Fred Wilmot-Smith for their very helpful comments on earlier drafts. Finally I would like to thank the journal's anonymous reviewers for their valuable suggestions.

1 eg E H Levi, An Introduction to Legal Reasoning (University of Chicago Press 1948), 1-3; L L Weinreb, Legal Reason: The Use of Analogy in Legal Argument (CUP 2005), 1-5.

${ }^{2}$ R A Posner, How Judges Think (Harvard University Press 2008), 180-91; L Alexander and E Sherwin, Demystifying Legal Reasoning (CUP 2008), ch 3.

${ }^{3} \mathrm{~N}$ MacCormick, Legal Reasoning and Legal Theory (OUP 1978), ch 7; R M Dworkin, 'In Praise of Theory' (1997) 29 Arizona State LJ 353.
} 
In this paper I will argue that there is some merit in most of these views. This is because there is not one type of analogical reasoning in the common law, but several different types. Some of the disagreements about analogical reasoning stem from the fact that these differences are not very clearly marked in the common law itself, nor in theoretical discussions of the common law. Many of the pieces of the puzzle of analogies are, I think, already available in the theoretical literature. The key to understanding analogies lies in how we put these pieces together, rather than in their wholesale replacement. I will distinguish three types of analogies: classificatory analogies, close analogies and distant analogies.

Classificatory analogies are those used in the process of characterising the facts of a case for legal purposes. This is often because a particular categorisation would bring the facts under an existing legal rule and settle the result of the case. When the characterisation is unclear, decided cases with similar facts are called in aid to help settle the question. Close analogies, by contrast, are used in helping to resolve a novel legal issue raised by the facts of the case. Where there is no clear law on that issue, the way that this type of issue has been dealt with in other branches of the same legal doctrine is brought to bear. The problem is not how to characterise the facts, but how to resolve the novel issue raised by those facts. Distant analogies are relied upon for the same reason as close analogies. They differ from close analogies in being more doctrinally distant from the issue to be resolved. Consequently, while close analogies are regarded as very strong reasons for reaching a particular result, distant analogies merely support, or provide a reason in favour of doing so. But it is not just the role of these different types of analogies that distinguishes them. Their justifications also differ. The use of classificatory analogies rests on rule of law concerns for consistency in the application of the law, while the use of close analogies is derived from the collateral force of precedent. Distant analogies, on the other hand, derive what rational force they have from a concern with general doctrinal coherence in the law, and their value is consequently far more variable than close analogies. Understanding these different types of analogies helps to explain the disputes over the normative force of analogical reasoning and helps to explain the widely divergent views of its significance.

\footnotetext{
${ }^{4} \mathrm{~J} \mathrm{Raz,}$ 'Law and Value in Adjudication' in The Authority of Law (2 ${ }^{\text {nd }}$ edn, OUP 2009); S Brewer, 'Exemplary Reasoning: Semantics, Pragmatics, and the Rational Force of Legal Argument by Analogy' (1996) 109 Harv L Rev 923.
} 
Of course, to identify three basic types of analogical reasoning is not to claim that every instance of analogical reasoning can be fitted easily into one of these categories, nor that the distinction between close and distant analogies is always clear-cut. Rather it is to say that the typology is sound and covers enough instances for it to help advance our understanding both of analogical reasoning itself and the theoretical disputes about its nature. One underlying theme in this paper is that even if common law reasoning is best understood as a form of reasoning with rules, ${ }^{5}$ it is not simply reasoning with rules. The different types of analogy rely in part on legal doctrine having a structure which is (at the least) rule-like, but they also depend upon legal doctrines having rationales that make sense of their existence and content. Both dimensions of legal doctrine are necessary to understand the operation of analogical reasoning in the common law. In the course of this analysis, I also hope to shed a little light on two other issues: the nature of legal concepts and the nature of the doctrine of precedent. The use of classificatory analogies involves the use of cases to determine the characterisation of novel facts, but it also indicates that decided cases are integral to the constitution of legal concepts. The existence of close analogies, meanwhile, helps to make sense of some of the disputes over specifying the ratio of a precedent.

The paper will proceed as follows. In the first section I make a few observations about the nature of legal reasoning in general, to give some sense of the approach taken in the paper. In the following three sections I consider each type of analogy in turn, explaining its structure and the basic rationale for its deployment. Because my focus is on the common law, I will limit myself to the use of cases as the source of analogies. Statutes are sometimes also used as a source of analogy, but their use is more limited and complex that the use of cases, and there is much more variation within the Common Law tradition over their use. ${ }^{6}$

\section{Legal Reasoning}

It is common enough to speak about 'analogical reasoning', 'reasoning by analogy' or the 'logic of analogies' as part of legal reasoning. But what is legal reasoning? At a basic level, legal reasoning deals with the steps and the inferences made by lawyers in reaching a conclusion over the state of the law on some issue. For instance the fact that

\footnotetext{
${ }^{5}$ eg Alexander and Sherwin (n 2), ch 2.

${ }^{6}$ R S Summers and N MacCormick (eds), Interpreting Statutes: A Comparative Study (Dartmouth 1991), 369; MacCormick (n 3) 192-4; D Hunter, 'Reason is Too Large: Analogy and Precedent in Law' 50 (2001) Emory LJ 1197, 1233-37.
} 
there is a binding precedent that applies to a case requires that a court either follow the decision (ie reach the same outcome as the precedent) or distinguish it. Other types of considerations are raised because they count in favour or against a particular conclusion. The types of considerations that can be pressed in legal argument are very varied. A contrast is often drawn between legal considerations and non-legal considerations, though there are at least two different contrasts that can be marked by these terms. In one sense, a legal consideration is any consideration that is regarded as legally permissible or relevant, ie that it would not be inappropriate to take into account in reaching a decision. At present the common law treats some considerations, such as the truth of religious views, or the desirability of party-political outcomes, as legally inadmissible, ie as not in principle available to weigh in its considerations. ${ }^{7}$ But it is generally very permissive about the types of considerations that can be raised. Within those considerations regarded as admissible, however, there are some that are regarded as distinctively legal considerations, such as precedent, dicta, and legal principles, as opposed to non-legal considerations such as moral values, practical constraints, or consequential effects. ${ }^{8}$

Legal reasoning is concerned with the ways in which different considerations contribute to the determination of the law. Like any sort of reasoning it can be studied as a psychological phenomenon and as a normative practice. Psychological studies focus on how people in fact come to conclusions in some area: what things influence their thinking, and what factors play a key role. ${ }^{9}$ From a psychological perspective fallacies and biases are just as much a part of human reasoning as 'rational' constraints, and there is a great deal to be learnt about human reasoning from such empirical research. Approaching reasoning as a normative practice, on the other hand, is concerned with understanding what constitute good canons of reasoning in a particular branch of human endeavour, ie how reasoning is supposed to be carried out when it is done well. Of course, the psychological and normative approaches complement each other and are, to a degree, mutually dependent. Neither approach can be pursued in isolation from the other, though each has its own emphasis. What constitutes a 'fallacy'

\footnotetext{
${ }^{7}$ The exact position is more complicated, since the law could direct the courts to rule on these matters or to use them.

${ }^{8}$ This is not to say that legal considerations are (or need be) non-moral, or non-practical, or nonconsequential, simply that there are non-legal moral values, practical constraints and consequential effects.

${ }^{9}$ See, for example, the essays in K J Holyoak and R G Morrison (eds), The Oxford Handbook of Reasoning and Thinking (OUP 2012).
} 
or a 'bias' depends upon what constitutes sound reasoning. And what constitutes sound reasoning in a field depends in part on what practitioners in the field do and what they judge appropriate to do. This is not to say that the standards of reasoning in a particular field are self-validating, as if agreement among participants over what constitutes a sensible approach is sufficient to make that approach cogent. Those who believe in astrology may follow certain standards of reasoning in coming to their predictions about a person's future, but that does not, on its own, make those standards rationally plausible. So a normative approach to reasoning also seeks to vindicate the standards used in a particular area, and may be led to criticise and question some (or even all) of the standards currently endorsed. The focus in this paper is on the normative approach to legal reasoning, ie on what is treated as sound reasoning by common lawyers.

Legal reasoning in the common law is often characterised as a form of reasoning with rules. ${ }^{10}$ Some accounts regard reasoning by analogy as analysable in terms of rules, ${ }^{11}$ whereas others regard it as a process that does not rely on rules, for good ${ }^{12}$ or ill. ${ }^{13}$ The approach in this paper is more complex, as will become apparent in the sections below. The common law certainly has a rule-like character: the concepts, doctrines, and areas form a structure which can be analysed in terms of their elements and their application. But the common law is more provisional and partial than statutory rules. It is more open to being developed in cases, due to the processes of distinguishing and analogy, and it often provides only a general sketch of the structure of an area. In addition, the common law regards the rationale for a doctrine as integral to its content. I will write below of legal doctrines being partly constituted by 'legal rules', but I mean by this the looser and more relaxed standards that are characteristic of the common law. The role of such rules differs from one form of analogical reasoning to another. This is another reason, then, why it is important to distinguish the different types of analogies.

Some theorists have written of there being a 'logic' of analogical reasoning. ${ }^{14}$ I will not adopt this terminology, since it implies a degree of precision and structure that is

\footnotetext{
${ }^{10}$ Alexander and Sherwin (n 2) ch 2; F Schauer, Playing by the Rules (OUP 1991) 174-87; Raz (n 3).

${ }^{11}$ Brewer (n 4); P Westen, 'On "Confusing Ideas": A Reply' (1982) 91 Yale LJ 1153, 1162-64.

${ }^{12}$ Levi (n 1); Weinreb (n1); G J Postema, 'A Similibus ad Similia: Analogical Thinking in Law' in D E Edlin (ed), Common Law Theory (CUP 2007), 113-21.

${ }^{13}$ Alexander and Sherwin (n 2) ch 2; Posner (n 2) 180-91.

${ }^{14}$ Brewer (n 4) eg 927, 928, 942, 964; D Walton, C Reed and F Macagno, Argumentation Schemes (CUP 2008), ch 2.
} 
not generally found in the common law. It can also be misleading. Logic, in its strict sense, concerns the relations of entailment between the premises and conclusions of an argument. Reasoning, by contrast, is concerned with what there are reasons to believe or do. Reasoning involves the use of logic, but logic is only one aspect of reasoning. ${ }^{15}$ What the language of 'logic' does highlight, however, is that analogical reasoning has distinctive forms, ie that it involves a pattern or process that can be explained, and not simply an intuitive recognition of the relevance of other cases.

\section{Classificatory analogies}

The first category of analogical reasoning I will discuss has attracted less theoretical attention than the other two, but it is the category that makes most sense of the idea that analogies are based upon the similarities between the facts of two cases, and it plays a very significant role in day-to-day legal practice. Classificatory analogies are used to help determine the legal characterisation of the facts of a case. Is a person paid to carry out work for another an 'independent contractor' for the purposes of vicarious liability? ${ }^{16}$ Is the obligation of an agent to visit potential purchasers of the principal's goods a 'condition', entitling the plaintiff to terminate the contract if the performer is absent, or merely a 'warranty' entitling the plaintiff to sue for damages? ${ }^{17}$ This is not the only use for classificatory analogies in the law. Legal categories themselves often belong to more abstract categories: being drunk, for instance, can constitute a form of intoxication in the criminal law, while intoxication is one type of excuse, and excuses one type of criminal defence. But in the discussion that follows, I will focus on the classification of facts, though similar considerations apply to the higher-order categories as well.

An initial line of thought may be that the use of analogies in classification is due to the vagueness and open texture of legal rules. The application of a legal rule requires that the categories used in the rule apply to the facts of the case. Whether a category applies to the facts depends upon it satisfying the criteria for belonging to that category. Sometimes it is unclear whether the criteria are satisfied: has this breach of a contractual term deprived the innocent party of 'substantially the whole benefit' of the contract? ${ }^{18}$ Where the answer isn't clear, lawyers turn to cases with similar facts to see

\footnotetext{
${ }^{15}$ See G Harman, Change in View: Principles of Reasoning (MIT Press 1986), chs 1 and 2.

${ }^{16}$ Ready Mixed Concrete $v$ Ministry of Pensions [1968] 2 QB 497.

${ }^{17}$ Schuler AG v Wickman Machine Tool Sales [1974] AC 235 (House of Lords).

${ }^{18}$ Hongkong Fir Shipping v Kawasaki Kisen Kaisha [1962] 2 QB 26 (Court of Appeal, Eng).
} 
how courts have resolved them in order to find some guidance. There are a number of reasons, however, for thinking this analysis is too simple. First of all, it is sometimes uncertain or unclear what the applicable grounds for a classification are. A group of cases may have been held to fall within a particular category, but either no proposed test or analysis of the basis for the classification has been given or none has achieved widespread acceptance. ${ }^{19}$ Secondly, there may be accepted grounds for the classification, but grounds that are regarded as partial, merely indicating the sorts of considerations relevant to the classification without providing a comprehensive account. It is rare for a case, or even series of cases, to provide a set of necessary and sufficient conditions for classification. Thirdly, even if there are clearly accepted grounds for the classification, understanding the content of the grounds will depend in part on familiarity with the cases decided according to it. This is not only due to the very abstract way in which some grounds are couched (eg a duty of care in negligence requiring there to be 'proximity' between the partie ${ }^{20}$ ). Understanding the legal meaning of 'intention', or 'employee', or 'trust', turns in part on knowing how those terms have been applied in particular cases. The dependence on decided cases also helps to explain why the classification of a case may be arguable even though it does seem to fall squarely under the accepted grounds, since there may be similar cases that have been held not to fall within the category.

Besides the grounds for a classification and instances where it has been applied, there are two further aspects of legal knowledge that lawyers bring to bear in classifying a situation as belonging to a legal category. The first is an appreciation of the legal purpose(s) for which the category exists, ie what the role or purpose or function of the category is in that area of the law. The classification of a worker as an 'employee' in the law of vicarious liability, for example, has a different point to the classification of the same worker as an 'employee' in taxation law. ${ }^{21}$ The second aspect of legal knowledge that a lawyer brings to classification is an understanding of the network of connections between the category in question and other legal concepts within its field of law. The classification of a contractual term as a 'condition' is influenced by the way that the concept is related to cognate terms ('warranties', 'innominate terms'). So the

\footnotetext{
${ }^{19}$ See the discussion of cases on the Fourth Amendment to the US Constitution ('The right of the people to be secure in their persons, houses, papers, and effects, against unreasonable searches and seizures, shall not be violated, ...') in Weinreb (n 1) 55-63 (and Posner (n 2) 190-1).

${ }^{20}$ Caparo v Dickman [1990] UKHL 2 (House of Lords).

${ }^{21}$ This doesn't make decisions from other areas irrelevant, but means that they have to be used with care.
} 
classification of a term in a contract as a 'condition' will depend on: (a) the accepted characterisation of a condition; (b) the cases where the classification of a term has been in issue; (c) the role that 'conditions' play within contractual liability (entitling the innocent party to terminate for breach); and (d) the interrelation with other aspects of contract law (such as the parties' ability to designate terms as conditions). These four dimensions exist both in categories created by the law (eg easement, cestui que trust) and in non-legal categories adopted by the law (eg intention, financial advisor, cause). Even in the latter case, the adopted category differs from its non-legal counterpart, due to its content being dependent upon the way the category has been applied in decided cases, the role of the category within the law, and its connections to other aspects of the relevant legal doctrine.

This picture of legal categories has affinities with work done in the philosophy of concepts. ${ }^{22}$ 'Classical' (and 'neo-classical') theories of concepts emphasise the existence of conditions or criteria for the identification of the members of the class falling under the concept. 'Prototype' theories, by contrast, emphasise the role of exemplars in constituting a category, with members of the category being identified through sharing a sufficient similarity to the exemplars (eg the concept of 'furniture'). 'Theory' theories of concepts emphasise that the application of a concept is determined by a broader field of thought and the role the concept plays in that field (eg the concept of 'force' in mechanics). Pluralistic theories of concepts, meanwhile, regard all of the preceding as aspects of a satisfactory theory of concepts. ${ }^{23}$ In the case of legal categories a pluralistic conception seems closest to the mark: legal categories generally have some form of characterisation, exemplary instances, and play a role or function within a wider network of concepts.

One important upshot of a pluralistic conception is that while legal concepts can have a very settled shape, they can also be quite fragmented and unsettled. Some concepts will be associated with a set of cases that share a widely accepted characterisation, and the role of the concept in its legal context will be fairly uncontroversial, as will its relationship to closely connected legal concepts. But in the

\footnotetext{
${ }^{22}$ For a recent overview, see E Margolis and S Laurence, 'Concepts', Stanford Encyclopedia of Philosophy, (Fall Edn 2012) <http://plato.stanford.edu/archives/fall2012/entries/concepts/> accessed 20 July 2013.

${ }^{23}$ Strictly speaking, all of these elements are at play in 'complex' concepts, while there are 'simple' concepts (like 'yellow', or 'round') that may be accounted for using one of the elements alone.
} 
case of other concepts there will be competing accounts of the best characterisation of the cases, and of the role of that concept in its legal context. ${ }^{24}$ The difference between 'settled' and 'unsettled' legal concepts is one of degree, and is not immutable. Over time a settled concept may become unsettled, and vice versa. Nonetheless, the two share a lot in common when it comes to the use of classificatory analogies. Take the case of relatively settled concepts first. Analogous cases are cited here where a case has aspects that would support its placement within the category as well as aspects that would support placing it outside. What makes a new case 'similar' to an existing case depends in part on why the courts in the earlier cases attributed a particular category to the facts of the earlier case (or refused to do so). The features that the court highlighted as contributing to the classification, and those that it regarded as unimportant, will help to provide points of comparison. In some cases the similarity to existing cases will provide very strong support for adopting the classification in dispute. In other cases, the similarity will provide only weak support. And there will be cases in between these two poles. ${ }^{25}$ In English criminal law, for instance, a defendant must do an act that is 'more than merely preparatory' to the commission of a crime in order to be guilty of an attempt. This has been interpreted to mean that the defendant must have 'embarked upon the crime proper', and not merely put herself in a position to commit the offence. ${ }^{26}$ But how close must a defendant be to the complete crime for their acts to be 'more' than merely preparatory? Cases such as those that hold that an armed defendant who is about to enter a shop is merely at the preparatory stage of robbery, ${ }^{27}$ whereas defendants who have broken the outer lock on a door but not entered the premises have gone beyond the preparatory stage of a burglary, ${ }^{28}$ provide analogies for the different facts of later cases.

Ultimately, what makes a case 'sufficiently' similar to be a candidate for characterisation under a concept is a matter of judgement. What will be sufficient to pass this threshold is not something that can be codified or fully articulated, since it

\footnotetext{
${ }^{24}$ The second possibility has obvious affinities to Dworkin's theory of 'interpretive' concepts (Law's Empire (Harvard University Press 1986), ch 2), but is not restricted to the types of concepts he discusses.

${ }^{25} \mathrm{~A}$ further complication is that not all analogous cases are of equal value. Some of the existing authorities will be regarded by lawyers as anomalous or dubious decisions, due to their relationship to the other dimensions of the concept, and relying on them to support a classification will be of very limited value.

${ }^{26}$ Gullefer [1990] 1 WLR 1063, 1066 (Court of Appeal, Eng).

${ }^{27}$ Gullefer (n 26).

${ }^{28}$ Boyle and Boyle (1987) 84 Cr App R 270 (Court of Appeal, Eng).
} 
involves bringing all of the different dimensions of a concept together to form the overall judgement. Those theorists who have emphasised that the use of analogies cannot be reduced to the application of rules or criteria are highlighting the fact that mastery of a concept is rarely reducible to possessing a set of necessary and sufficient conditions for its use. ${ }^{29}$ The complicated set of ingredients that are involved in possessing a concept means that there is a complex overall judgement involved in seeing a case as falling under a concept, and in seeing a case as arguably falling under a concept. To make that overall judgement involves a step beyond the awareness of the relevant aspects of a case. This is not to say that drawing classificatory analogies does not involve the use of accepted criteria for the application of a concept (where they are available). It is just that this is not all there is to applying a concept.

In the case of unsettled concepts, it might be thought that analogies to existing cases are important because of the disagreements between lawyers over the proper characterisation of a concept. Although lawyers have different views about the concept, they largely agree about the cases that fall under the concept, and so analogies have a larger role to play. But this line of thought presupposes that a case can be seen as 'analogous' to another case independently of the characterisation. If the disagreements over the characterisation of the concept are radical enough, then whether a case is analogous to an existing case may itself be controversial. Nonetheless, the basic analysis of analogies holds good for unsettled concepts. It is just that what is analogous for one characterisation of the concept may not be analogous for another. I will ignore the complication of unsettled concepts in the following discussion, since it does not fundamentally alter the points about the use of classificatory analogies.

Classificatory analogies assist in deciding whether or not to allocate a new case to an existing category. The use of analogies in classification makes sense of the common idea that analogies are based on relevant similarity between the facts of cases. The similarities that matter are those related to the characterisations and functions of the concept in the existing cases, and is a matter of degree. Sometimes both the inclusion and the exclusion of the new case would be well supported by the shape of the existing concept. In these cases a court has to decide whether, on balance, there is sufficient similarity to the existing cases to include the new case. In a sense the use of classificatory analogies involves an exercise in 'artificial reason' of the kind sometimes

\footnotetext{
${ }^{29}$ See Weinreb (n 1) 123-38; Postema (n 12) 113-21.
} 
thought characteristic of the law. ${ }^{30}$ It is 'artificial' because it goes beyond what would be thought rational in non-legal contexts. If the classification of a novel set of facts is unclear, it would normally be enough to conclude just that, or if a decision was needed, to base the classification on considerations of what would be the best in the circumstances of this case, or for the future determination of cases of this kind. It is a particular feature of legal decision-making that the classification should also be consistent with previous cases, ie with the existing decisions that the law has made, even when these earlier cases could quite reasonably have been decided otherwise. The point is that even if the line being drawn between cases is, in a significant sense, arbitrary, it is being drawn in a systematic way, rather than leaving arguable cases to be decided on an ad hoc basis by individual courts. The use of analogies cannot of course eliminate the need for courts to make judgements about the relevant similarities, but it seeks to reduce and constrain the degree of individual judgement involved. It thereby seeks to bring the use of classification closer to the rule of law ideal where the outcome of the case does not depend upon the individual views of the particular decisionmaker, but upon the common understanding of what the law requires.

\section{Close Analogies}

The second major use of analogies in the common law is to help settle a novel legal issue raised by a case. The characterisation of the facts may be clear enough, but there may be no directly applicable legal authority resolving that issue. Can the National Society for the Prevention of Cruelty to Children (NSPCC), a private charity, refuse to disclose the name of an informant who it is claimed made untrue allegations against the claimant? ${ }^{31}$ In these sorts of cases, lawyers and courts have a variety of legal materials to which they can turn, such as dicta, legal principles, and persuasive authorities. But a very common line of argument is that there is an analogous case that bears on the issue. As noted in the introduction, some of these analogies ('close' analogies) are regarded as providing strong support for a particular resolution of an issue, whereas others are regarded as simply helpful or suggestive ('distant analogies'). Simplifying somewhat, this is because close analogies operate within legal doctrines, whereas distant analogies operate across different doctrines.

\footnotetext{
${ }^{30}$ eg Coke's famous view in Case of Prohibitions [1607] EWHC KB J23; 12 Co Rep. 64; 77 ER 1342.

${ }^{31} D$ v NSPCC [1978] AC 171 (House of Lords), discussed by Raz (n 4) 203-4 and

M A Eisenberg, The Nature of the Common Law (Harvard University Press 1988), 90-2.
} 
The use and force of close analogies rests on the structure of legal doctrine. Many accounts of legal analogies are incomplete because they focus in isolation on the two cases that are analogous and the relationship between them. The relationship between the cases must instead be seen through the prism of surrounding legal doctrine. A case raises a legal issue, and a legal issue depends upon the way in which the facts of the case are characterised in legal terms. A set of facts must be located within some field or fields of law, such as raising a question of contract law, or administrative law. These fields of law form systematic networks with distinctive structures. The most relevant feature for reasoning by close analogy is the way in which fields of legal doctrine form nested structures, from very broad and abstract doctrines to very detailed compartments of law. The law of torts, for example, has an array of actions-intentional torts, torts of negligence, strict liability torts. Within an individual tort there will often be further subcategorisations: the law of negligence, for instance, covers occupiers, professional practice, and products liability, among others. Within professional negligence there is medical negligence, negligence of lawyers, accountants, etc. As one drills further down the law becomes more and more specialised and more and more fine-grained. Specialised areas are regarded as both distinctive-dealing with a particular subjectmatter that raises its own distinctive considerations-and part of a wider field that gives the general shape to the area.

This is not to say that the common law as a whole has a single, unified structure. Legal doctrine can be organised (as shown by many textbooks) in different ways, for example in terms of particular types of parties, like landowners and road drivers, or particular types of activities (or subject-matter), such as higher education and consumer products, as well as being organised in terms of particular types of liability. Similarly, there are different ways of organising sub-categories, for instance in terms of the loss involved, such as property damage versus economic loss. These different ways of organising legal doctrine highlight something distinctive about particular aspects of the law, and how that distinctiveness feeds into the law as it applies to a certain type of party or activity. The different ways of organising legal doctrine thereby provide additional ways in which to relate a case at hand to earlier cases.

A case raising a novel issue arises at the ground level, as it were. The circumstances that have occurred, and the type of legal remedy or relief that a party is seeking, will need to be located within the framework of legal doctrine and given a legal characterisation. The initial question will be what sort of legal problem the facts raise, 
and how it can be classified for legal purposes. The characterisation of the issue, and the location of the question within the specialised area where it arises, gives rise to the scope for close analogies. Because doctrine is divided into more and more specialised areas, the other sub-divisions within the same doctrine share the same basic structure and raise the possibility that the same type of issue has arisen in a closely related field. Subdivisions facilitate borrowing from cognate areas of doctrine. The borrowing may be from a doctrinal field within a closely related sub-division to the case in question, or it may be from somewhat further afield within that doctrine. The identification of analogous cases, then, is a matter of finding cases in cognate areas of the doctrine that address the same type of legal issue, and the closer the legal area of the analogous case to the area of the current case, the closer the analogy.

Identifying a related case is only the first step in the use of analogies, however. The second step is how that case bears on the issue in the current case. That depends not on the fit between the issues in the two cases, but on the rationale for the resolution of the issue in the first case. Whether a close analogy supports the same resolution of the issue in the current case depends upon why the court came to its decision in the first case. If it reached its decision for reasons that are pertinent to the current case, then that supports the same resolution. But if it relied on the distinctive character of the subdivision in reaching its decision, this may not be so. In $D \vee N S P C C$, for example, the plaintiff sought disclosure of the identity of an informant who had falsely accused the plaintiff of ill-treating her child. ${ }^{32}$ It was settled law that the police could not be required to disclose the identity of their informants, but the NSPCC was a private charity aimed at protecting children from cruelty. On the other hand, the NSPCC had been invested with a statutory power to bring legal proceedings to have neglected children taken into state care: a power the legislation also conferred on local authorities and the police. The House of Lords reasoned that in the course of investigating cases of child neglect with a view to possible care proceedings, the immunity from disclosure that the police would enjoy if investigating a case should also be applicable to the NSPCC. The reasons behind the non-disclosure immunity (to encourage those with information of wrongdoing who might be reluctant to come forward without an assurance of confidentiality, eg neighbours) were equally applicable to the charity in these circumstances.

\footnotetext{
32 [1978] AC 171 (House of Lords).
} 
Understanding these two stages is important, because the identification of analogies is often said to belong to the 'logic of discovery', parallel to the process in scientific discoveries. ${ }^{33}$ It is sometimes assumed that there is nothing useful to be said about the process of identifying analogies, as it depends on an intuitive appreciation of the similarity between the cases, ${ }^{34}$ or depends upon recognizing the relevance of the rationale of the other case to the case at hand..$^{35}$ Alternatively, the process of drawing analogies in ordinary life, with its characteristic psychological patterns of seeing similarities between different objects and processes, is invoked to provide content to the identification. ${ }^{36}$ The preceding analysis sees the identification of close analogies as a more structured process than these approaches allow. Identifying analogies is a basic skill that lawyers acquire in the process of their legal education. It is a question of knowing where to look for possible authorities (closely related doctrinal areas) and what to look for (the same type of issue). Of course, for an experienced lawyer with a wide knowledge of the law, some analogies will just spring to mind, because the lawyer does not need to search her mind or library to exercise the skill. But this type of 'intuitive' judgement is characteristic of most cognitive skills: once mastered they can be exercised in an unselfconscious way.

A key to understanding the nature of close analogies lies in their relationship to the doctrine of precedent as it is practised in the common law. Indeed neither the doctrine of precedent itself nor close analogies can be properly understood except by reference to each other. To appreciate this, it is helpful to begin by considering how lower courts deal with recent decisions of appellate courts in their own hierarchy. If an appellate decision is merely analogous, it means that the lower court is not strictly bound by the decision. On an orthodox understanding of the doctrine of precedent, lower courts are only bound by the ratio decidendi of an appellate decision. The ratio is, roughly speaking, the ruling on the issue(s) of law contested before the court. ${ }^{37}$ The ruling holds that in the type of circumstances that arose in the case (ie given the facts $a, b, c$ ),

\footnotetext{
${ }^{33}$ Hunter (n 6) 1245-50; Posner (n 2) 183.

${ }^{34}$ eg Brewer (n 4) 954, 964.

35 eg MacCormick (n 3) 185-6, 190-1. Similarly Raz (n 4) 203-4.

${ }^{36}$ eg Hunter (n 6) 1214-29; Weinreb (n 1) 122-38; Postema (n 12) 117-24. For an overview of the psychological literature on analogical reasoning, see K J Holyoak, 'Analogy and Relational Reasoning' in Holyoak and Morrison (n 9).

${ }^{37}$ R Cross and J W Harris, Precedent in English Law (4 ${ }^{\text {th }}$ ed, OUP 1991), ch 2; N MacCormick, 'Why Cases have Rationes and What These Are' in L Goldstein (ed), Precedent and Law (OUP 1987).
} 
certain legal consequences follow (eg liability to pay damages, duty to exclude evidence). Where the ratio is applicable to a later case, ie where the same types of facts are present, the later court is required to reach the same conclusion, unless the case is distinguishable. There is, of course, some dispute among common lawyers and theorists over how exactly to ascertain the ratio of a case. ${ }^{38}$ In particular, there is disagreement over how narrowly or broadly the facts should be characterised, and how much weight should be given to the precedent court's own characterisation of the facts. But in many cases it is clear enough, and in practice, for reasons that will be discussed below, the different views of the ratio rarely make a great difference to the outcome of a later case.

Where an earlier decision is merely analogous, the ratio of the decision does not apply to the facts of the later case. For instance the type of defendant in the earlier case may have been significantly different (a doctor versus an auditor), or the type of damage (physical harm versus property damage), or the manner in which loss was caused (direct physical effect versus reliance on a verbal communication). But due to the nested nature of legal doctrines, the earlier case is relevant to the later case because at a higher level of generality the cases are comparable (eg characterised in terms of professional advisors, or material loss, or causation). If the lower court concludes that the rationale for the earlier decision, ie the reason(s) given by the earlier court for its conclusion, is applicable to the facts of the later case, then it takes the view that the outcome should be followed unless the facts of the later case provide some basis for reaching a different conclusion.

Close analogies, then, have a strong normative force for lower courts. They are not merely ' $a$ ' reason to reach the same outcome as reached in the analogous case, ie one reason to be weighed with others in reaching a result, but a sufficient reason in and of itself to do so in the absence of a strong reason to do otherwise. In the limiting case of a very recent appellate decision with a rationale that clearly covers the new facts, the force of the analogy will be little short of that of a binding precedent. ${ }^{39}$ In other cases the force of the analogy will be somewhat weaker, and the scope for distinguishing correspondingly greater. This is due to a number of factors. First of all, it is an

\footnotetext{
${ }^{38}$ Compare A L Goodhart, 'Determining the Ratio decidendi of a Case' (1930) 40 Yale LJ 161; Levi (n 1) 1-3; A W B Simpson, 'The Ratio Decidendi of a Case and the Doctrine of Precedent', in A G Guest (ed), Oxford Essays in Jurisprudence (OUP 1961); with Cross (n 37) and MacCormick (n 37).

${ }^{39}$ Hence Eisenberg's claim that reasoning by analogy and from precedent are 'substantively equivalent': (n 31) 94.
} 
oversimplification to treat cases as having a single rationale. It is far more common for a range of considerations to be advanced in favour of the decision in the case (in both individual judgments and concurring opinions), not all of which will transfer to the new context. So the later court must consider these different reasons in determining how the analogous case applies. Secondly, how 'close' a close analogy is to the case at hand is a matter of degree. As analogies become more distant, the contextual differences loom larger, and the reasons for adopting the analogy less compelling. Similarly, the older an analogous case is, the more likely that surrounding doctrine has moved on, and the less straightforward becomes the applicability of the earlier court's rationale. There is, thirdly, the fact that an analogous case may have been doubted or criticised in subsequent decisions, which may encourage a later court to confine the decision to 'its own facts'.$^{40}$ Finally, a court may be dealing with a decision that it has the power to overrule, in which case it will be more at liberty to question the result in an earlier decision, or to propose an alternative rationale for the decision.

It can be seen from the preceding analysis that the justification for close analogies is bound up with the justifications for the doctrine of precedent itself. Precedent requires courts to defer to earlier decisions, whether or not they agree with those decisions. This promotes a degree of predictability and consistency in decision-making, an important goal in light of the multiplicity of decision-makers within a court system. In an institutionalised setting like the law, it can be better to have judges defer to decisions of appellate courts, than for each judge to decide each case on its merits. But the doctrine of precedent in the common law has its particular shape because of the way that close analogies complement precedents. The orthodox conception of a precedent as having a ratio which is strictly binding (ie must be followed or distinguished), suggests an all-ornothing relevance of authorities where determining the precise content of the ratio is vital. It suggests that precedent is simply a form of reasoning with rules, with the ratio constituting a legal rule. ${ }^{41}$ But in practice the legal effect of a precedent is extended by the use of close analogies, with the difference between a binding precedent and a close analogy being one of degree. This helps to explain why the common law has always been rather relaxed about ascertaining with precision the ratio of a case, and also why

\footnotetext{
${ }^{40}$ The fate, for instance, of the House of Lords decision in Junior Books v Veitchi [1983] 1 AC 520 on recovery for pure economic loss in negligence.

${ }^{41}$ For some doubts about conceiving rationes as rules, see J F Horty, 'The Result Model of Precedent' (2004) 10 Legal Theory 19; G Lamond, 'Do Precedents Create Rules?' (2005) 11 Legal Theory 1; N Duxbury, The Nature and Authority of Precedent (CUP 2008), pt 3.
} 
the competing accounts of how to determine the content of a ratio matter more in theory than in practice. Whether the result in an earlier case provides a binding precedent or a close analogy, it provides a very strong reason for being followed. But in neither case is it a conclusive reason, since the later case may still be distinguishable.

Analogies do not simply soften the cut-off relevance of precedents, however, they also serve to promote internal coherence within legal doctrines. The various subdivisions of legal doctrine are (ideally) developed with one eye on other cognate subdivisions. This reflects the fact that law is not simply a body of rules: it is a body of reasoned doctrines that are interconnected and interrelated. Legal doctrines are constituted not simply by groups of rules that regulate and create activities, but by the values and interests that rationalise and justify those rules and standards. Close analogies provide for both the extrapolation of existing doctrine to novel contexts, and also allow the courts to consider whether there is anything distinctive about the context that counts against simple extension. Like the practice of distinguishing, the use of close analogies injects a degree of context-sensitivity into the development of legal doctrine. Both rationes and close analogies provide default solutions to the novel case. Courts are left to make a final judgement of the appropriateness of their application, but the existence of a prima facie solution indicates where the burden of persuasion lies, thereby making the courts' task much easier in many cases.

What close analogies inject into the common law then, is a close regard for internal doctrinal coherence. Precedents serve a double function. They settle certain questions of law raised before them. The narrower the ratio of a case, the lower the level of generality at which it is pitched and the more limited its directly applicable range. But however narrow the decision, the basis for the decision is potentially applicable to a wider class of cases by way of close analogy. ${ }^{42}$ Conversely, the wider the ratio of a case, the higher the level of generality and the greater its range, but the greater the scope for distinguishing the decision and thus narrowing its application. Precedents thus have two dimensions to them: their rulings and the rationales for those rulings. These two dimensions play a key role in both binding precedents and close analogies.

\footnotetext{
${ }^{42}$ For an extreme example, see the judgment of Brooke LJ discussing the conditions for necessity to be a defence to murder in Re A [2000] EWCA Civ 254 (Court of Appeal, Eng), permitting the surgical separation of conjoined twin babies (who would otherwise both have died), even though it would inevitably result in the death of one of the twins.
} 


\section{Distant analogies}

How do distant analogies differ from close analogies? They are 'distant' because they do not stand in the same type of doctrinal relationship to the case to be decided. Like close analogies, distant analogies are raised where there is no binding authority on an issue in contention before the court. ${ }^{43}$ But unlike close analogies, they do not come from another department of the same doctrine within which the issue arises. Instead, the court must look further afield for a case where the same type of issue has been resolved. So distant analogies operate across or between legal doctrines, rather than within them. A case provides a distant analogy where two conditions are satisfied: (a) the issue arising in the current case and the issue resolved in the earlier case can be given a common characterisation; and (b) the rationale for the decision on that issue in the analogous case is applicable to the common characterisation.

Take for instance the well-known developments in the law in the United States concerning rights over oil and gas. ${ }^{44}$ The general common law rule is that the owners of land have property rights to everything which is on or below the land. But they do not have property rights over (otherwise unowned) things that move over their land, such as wild animals, unless and until they reduce them into their possession (the 'rule of capture'). This leads to the question whether the owners of land under whose property lies part of a reservoir of oil or gas has property rights in the oil and gas. It was decided that they did not, drawing in part on the analogy of English case-law on rights over groundwater. ${ }^{45}$ These cases had held that there was a right to extract water, but no ownership in the water until it was reduced into the possession of the land-owner. The question of the property rights in oil and gas could be analogised to the rights over groundwater because both involved fluids that circulated beneath more than one property and whose extent was uncertain (the common characterisation condition), and this characterisation was relevant to the rationale for the decisions in the English cases, ie these were the features that provided the basis for only a right to extract (the relevant rationale condition).

\footnotetext{
${ }^{43}$ Distant analogies are also used where a court distinguishes an otherwise applicable precedent by reference to another case.

${ }^{44}$ Discussed by Posner (n 2) 186-8 and Hunter (n 7) 1231-2. For a detailed analysis of the historical case-law, see T Daintith, Finders Keepers?: How the Law of Capture Shaped the World Oil Industry (RFF Press 2010), ch 2.

${ }^{45}$ The standard case is Acton v. Blundell (1843) 152 ER 1223, which was taken to represent the common law in the United States as well. In fact, the use of the groundwater analogy in the US was quite chequered: see Daintith (n 44) ch 2.
} 
Distant analogies play a less decisive role in legal reasoning than close analogies. As discussed earlier, later courts regard close analogies as very strong reasons in favour of the same conclusion, ie as sufficient on their own to support that result. Distant analogies, on the other hand, simply support, or provide a reason, in favour of an outcome-a reason than must compete with other reasons for and against the outcome. A later court is at liberty not to follow it if it regards the overall balance of reasons as being against it. This also means that the court is not constrained to distinguish the analogous case: it may simply conclude that, even taking the analogy into account, the overall merits support a contrary outcome. Distant analogies, then, are not grounded in an extended conception of the role of binding precedent. In addition because they do not derive from closely nested doctrine, their identification is more haphazard than close analogies, depending upon the lawyers involved in the case recognising a link to another case or legal doctrine. Here the language of intuition and 'discovery' is not out of place. ${ }^{46}$ Nonetheless, there is a deep-seated cognitive capacity to recognise patterns of similarity between phenomena, ${ }^{47}$ and the scope for recognising similarities is facilitated in the law by the widespread use of common categories, concepts and considerations in different branches of the law. And once a possible analogy is recognised, it must be possible to articulate the relevant similarities between them, ie to give them a common characterisation.

Still, given that the identification of distant analogies is less dependable than close analogies, and given their limited force, why does the common law make such widespread use of them? One line of thought that is often said to underpin their use is the idea that 'like cases should be treated alike' ${ }^{48}$ Given that the two cases are alike, they should both lead to the same outcome. Stated in this form, however, the application of this precept to distant analogies is open to question. After all, the two cases, while indeed alike in some respects, are not the 'same' since they differ in other respects. That is why they are merely 'analogous'. Perhaps then the basic thought could be reformulated to read that 'similar cases should be treated similarly'. But this raises the question of what it means to say that two cases should be treated 'similarly' when the court is not constrained to follow the analogy. One answer that has appealed to

\footnotetext{
${ }^{46}$ Above, n 33.

${ }^{47}$ See n 36 above and B A Spellman, 'Judges, Expertise. and Analogy' in D Klein and G Mitchell (eds), The Psychology of Judicial Decision-Making (OUP 2010).

${ }^{48}$ eg S J Burton, An Introduction to Law and Legal Reasoning ( $2^{\text {nd }}$ edn, Little, Brown and Company 1995), 40.
} 
many theorists has been to analyse distant analogies in terms of legal principles. The idea is that a distant analogy is relevant because it exemplifies and endorses a legal principle. ${ }^{49}$ The legal principle that justified the result in the analogous case is also applicable to the case before the court, and so supports the same outcome. But a principle is not a conclusive consideration: insofar as the two cases are similar, the same principle applies to both, but the differences between the cases may ultimately justify different outcomes. From this perspective, reasoning by analogy is essentially a form of reasoning from legal principles.

Attractive as this analysis may seem, it rests on the flexibility with which the term 'legal principle' is employed in legal thought. There are at least three common ways in which the term is used: (a) to refer to a general normative standard that rationalises and justifies a legal doctrine or a range of legal doctrines (eg no-one should profit from their own wrong); (b) to refer to a more abstract characterisation of the general significance of a case or series of cases (eg that damages are the standard remedy for breach of contract); and (c) to refer to any general consideration put forward to justify the result in a case. ${ }^{50}$ Once the three are disentangled, it can be seen that legal principles do not in fact hold the key to understanding distant analogies in the common law.

The most important sense of 'legal principle' is (a), since it involves a standard that not only links a situation with an outcome, but provides a justification for that outcome. Such principles are not simply rules or standards of a higher level of generality-they also involve the inherent appropriateness of the outcome in that situation (eg that wrongdoing merits some negative response, not a positive one). ${ }^{51}$ There are two difficulties in understanding distant analogies by reference to such principles. The first is that distant analogies need not invoke principles of this kind. The analogy between gas and oil and groundwater, for example, does not rest on there being a normative 'legal principle' applicable to both cases: instead, there are just good reasons for not recognising property rights in the common circumstances of the cases (eg the impracticality of such recognition). The second difficulty with this line of analysis is that it obscures the fact that analogical cases are regarded as significant because of the

\footnotetext{
${ }^{49}$ A view favoured, eg, by both MacCormick (n 3) ch 7 and Dworkin (n 3 and 'Reply' (1997) 29 Arizona State LJ 431, 446-7, 455).

${ }^{50}$ MacCormick seems to use all three (n 3) eg 152-3 (general normative standard), 169-73 (abstract characterisation), 156, 166, 167, 186 (general consideration).

${ }^{51}$ This is why some theorists think it important to distinguish rules from these sorts of principles, the locus classicus being R M Dworkin, 'Model of Rules I' in Taking Rights Seriously (rev edn, Duckworth 1978).
} 
resolution reached on the issue in question. It is not simply that there was a rationale in favour of the outcome in the analogous case, but that the rationale prevailed over any countervailing considerations. That those considerations prevailed in the analogous case supports a similar resolution of the issue before the court. Normative principles, by contrast, need not have prevailed in an earlier case to be relevant to the case at hand: that they were outweighed on the facts in the earlier case is neither here nor there. But analogical cases are cited precisely because of the resolution of the issue in the case.

The second use to which the term 'legal principle' is sometimes put, (b), is to refer to a more abstract characterisation of the ruling in an earlier case or series of cases, ie a rule at a higher level of generality. It might be said that the groundwater cases rest on the legal principle that where an underground fluid extends and flows beneath more than one property, a landowner has the right to extract that fluid from their own property, but no property rights in the fluid until it is captured. But although this type of 'legal principle' provides a useful summary of the effect of a decision, it does not account for why that principle was adopted. On its own it may be helpful in identifying a common characterisation between an existing case and the new case, but it does not itself explain why the characterisation is relevant.

Finally, 'legal principle' may simply be used compendiously to refer to any general justificatory reason (c). But then the claim that analogies are based on 'principles' is not making a distinctive claim, it is just re-phrasing the idea that they are based on the underlying rationale of the earlier case. That a case has a rationale does not mean that it rests on a single consideration, but that there is a reasoned basis for the conclusion reached by the court. The fact that the issues in the two cases can be given a common characterisation, and that the rationale for the decision in the earlier case is relevant to that common characterisation, makes the earlier case relevant to the later case.

If legal principles do not hold the key to distant analogies, what does? One proposal might be framed in the following way. In cases where distant analogies come into play the courts must reach decisions that will, in some sense, 'make' law. There will now be an explicit decision on an issue where previously there was none. But adjudicative law-making is importantly distinct from legislative law-making. What makes a decision an adjudicative rather than a legislative decision is that it is based on existing law. To say it is based on existing law does not mean that it is simply 'applying' 
existing law, nor that it is based exclusively on legal considerations. ${ }^{52}$ Instead it means that a court does not work from scratch, simply considering the substantive merits of the dispute before it. The initial framework for the decision, and the lead considerations for resolving it, must be derived from the law. Consequently, courts in the common law frequently turn to distant analogies where there is no directly applicable precedent or close analogy based on surrounding doctrine. This also accounts for the priority given to other legal considerations, such as legal principles and legal values, as well as dicta from earlier cases, in legal argument. This line of thought does help to explain the use of distant analogies, but as the example of dicta reveals, it does not establish that they need have a normative force that goes beyond the persuasiveness of their reasoning. If distant analogies were treated simply as views worthy of consideration by the court, ie as a possible source of guidance, that would satisfy the requirements of adjudicative law-making. ${ }^{53}$ To play that role they need not be regarded as supporting an outcome where the later court is unpersuaded by their reasoning.

Another possibility, by contrast, emphasises that analogous cases are regarded as relevant independently of the persuasiveness of their reasoning. Later courts do not simply consider the cogency of the earlier court's view, but regard the existence of the case as a reason in favour of following it. The cogency of the reasoning provides additional reasons in favour of the outcome, but the fact that another court made the decision is itself something to be taken into account. Hence a distant analogy has a weight for later courts that the argument of a textbook or advocate lacks. The reason for this, it is said, is that 'like cases should be treated alike', not because they instantiate legal principles, but simply as a matter of formal justice. Other things being equal, the result reached in the earlier case should be adopted in the later case as a matter of justice. Appealing as this line of thought may seem, it is in fact quite problematic. For one thing it implies that justice requires a decision to be followed in later cases irrespective of the merits of that decision. But absent additional considerations (such as reasonable reliance on the earlier decision), justice does not require the perpetuation of error-it requires its correction. ${ }^{54}$

\footnotetext{
${ }^{52}$ Cf Weinreb (n 1) 80-1.

${ }^{53}$ eg by treating them as having theoretical rather than practical authority. For a discussion see G Lamond, 'Persuasive Authority in the Law' (2010) 17 Harvard Review of Philosophy 16.

${ }^{54}$ See D Lyons, 'On Formal Justice' in Moral Aspects of Legal Theory (CUP 1993). And see A Marmor, 'Should Like Cases Be Treated Alike?' in Law in the Age of Pluralism (OUP 2007).
} 
A better justification that the previous three for the independent weight given to distant analogies is in terms of global coherence. If the reasoning in one case is applicable to another case with a common characterisation, then it supports the same outcome in the later case, since the law as a whole should be internally coherent. This is not a conclusive consideration, and it may be outweighed by other considerations, including the erroneousness of the earlier decision. A degree of global incoherence may be a price worth paying to reach the right result in the later case, but other things being equal it is better that the law is globally as well we locally coherent. Whilst this argument has merit, it presupposes that global coherence always provides at least some support for the extension of one decision into another area of law. But this is not obviously true. General global coherence, after all, is compatible with a good deal of local variation due to the plurality of values and interests that are in play throughout the law, and their varying importance in different departments of the law. How much weight should be given to a distant analogy depends upon how important it is that the legal doctrines in the analogical case and those in the current case correspond. In related fields this may matter a great deal, but in unrelated fields it will sometimes not matter at all. In the end, then, whether a distant analogy should be given a force that goes beyond the inherent persuasiveness of its reasoning depends upon the significance of the two areas taking a common view. The mere fact that a distantly analogous exists is not enough to show that there is a good reason for following it. There must be a real issue of coherence between the two areas for it to have a weight beyond the soundness of its reasoning.

In addition to the inherent limitation on distant analogies, they also suffer from a number of shortcomings in practice. First of all, since their identification is somewhat haphazard, it will normally be uncertain whether a court has all of the possible (and possibly conflicting) analogies before it. ${ }^{55}$ Secondly, distant analogies are prone to being cited uncritically in support of an outcome without close regard to the reasoning in the earlier case. Thirdly, their weight is often overstated, being treated as a clinching consideration in favour of an outcome without giving adequate attention to competing considerations raised by the merits of the novel case. This may be due to a pre-

\footnotetext{
${ }^{55}$ Unlike the oft-discussed case Adams v New Jersey Steamboat Co 45 NE 369 (NY 1896), where a state room in a steamboat was argued to be either like a sleeping berth on a railroad car or a room at an inn (with correspondingly different levels of liability): see Brewer (n 4) 1003-6, 1013-16, Weinreb (n 1), 41-5, Posner (n 2) 180-86, Alexander and Sherwin (n 2) 69-70, The court preferred the inn analogy, but had that analogy not been raised it might well have been swayed by the existence of the railroad analogy.
} 
disposition in favour of that outcome ('confirmation bias'), or simply amount to a shortcut to save the time and effort that would be required to assess the overall merits of the outcome. But the over-valuing of distant analogies may also be due to a 'halo effect' from close analogies: distant analogies may be given the sort of weight that only a close (or at least a closer) analogy would warrant. All in all, then, distant analogies have serious limitations, and a moderate scepticism about their use is not out of place.

\section{Conclusion}

The key to understanding analogical reasoning in the common law lies in recognising its different forms. With these forms in place, it is easier to appreciate the diversity of views that have been expressed about the nature of analogical reasoning. Close analogies, for example, are a cornerstone of common law reasoning, since close analogies complement and expand a narrow conception of the nature of precedent. The difference between a binding ratio and a close analogy can be very small. In many cases, it will matter little to a later court whether a precedent is strictly binding or 'merely' a close analogy: either way it should be followed unless it is distinguishable.

When it comes to distant analogies, it is easier to see the force in sceptical views of analogical reasoning. There are of course situations where maintaining coherence between or across different doctrines is a significant concern, but there are many other situations where the lack of synchronisation will matter little, if at all. What matters far more is the cogency of the reasoning in the analogical case, ie whether it presents a good case for dealing with an issue in a certain way. If it does, then naturally it should be adopted. So distant analogies can provide valuable assistance in resolving an issue. But they are apt to being given a weight in reaching a decision that exceeds their value. This points to the desirability of giving distant analogies a more modest role than they currently enjoy in common law reasoning. Even so, they are more than mere windowdressing, since inter-doctrinal coherence does matter in many situations.

All forms of analogical reasoning draw on the fact that legal doctrines are not simply a body of standards with a particular structure but a body of standards with an intelligible rationale that are nested within wider bodies of law. The operation of analogical reasoning relies both on the structure and the rationale of legal doctrines. Its importance lies in the way that it serves the courts' adjudicative functions: it enables courts to develop the law in ways that are both faithful to existing legal doctrine and sensitive to the novel context in which the law is to be applied. 